\title{
Treatment of cancer cachexia in the very advanced or terminal phase:
} a systematic review

\author{
Giuseppe Arvia, Stefano Giordani, Ismaeil Ghaderi, Sharon Nahas, Stefano Diana, Raffaella Indelli, \\ Beatrice Traverso, Giorgio Lelli
}

ADO Association - Casa della Solidarietà Hospice, Ferrara, Italy

\begin{abstract}
The therapeutic approach to refractory cancer cachexia represents an unmet need and an important research priority in the field of palliative care. Unfortunately, clinical studies in this area are scarce, both regarding nutritional and pharmacological approach. We performed a systematic literature search through Pubmed. The search algorithm considered: the clinical context, the related pathology, the therapeutic approach. The abstracts obtained were entered in a spreadsheet and analyzed in full text. The results were then analyzed according to the PRISMA method. Overall, 258 records were screened: 244 were excluded (not in English, n=44; no abstract, $\mathrm{n}=12$; literature reviews, $\mathrm{n}=108$; not relevant for not advanced phase or phase II studies, $\mathrm{n}=80$ ). The remaining 14 papers were read in full text: 10 were excluded (4 phase II studies, 4 including patients with a performance status score of $\geq 70 \%, 2$ including patients concomitantly treated by palliative chemotherapy). The remaining 4 studies of qualitative synthesis included: a study on megestrol acetate; a comparison between supportive treatment with/without melatonin; a placebo-controlled study on intravenous adenosine 5'-triphosphate; a comparison of indomethacin plus erythropoietin with/without nutritional support. The reported data do not allow us to draw any conclusion concerning the efficacy of pharmacological or nutritional treatment for cancer cachexia in very advanced or terminal phase and specific studies are, therefore, awaited.
\end{abstract}

Correspondence: Giorgio Lelli, Health Director, ADO Association - Casa della Solidarietà Hospice, via Veneziani 54, 44100 Ferrara, Italy.

Tel. +39.348.8277907 - Fax: +39.059.8375137.

E-mail address: lellidoc@gmail.com

Key words: cachexia, advanced cancer, terminal phase, systematic review.

Contributions: GL collected and analyzed data; GL, GA, SG, IG and SN wrote the manuscript; SD, RI and BT reviewed the manuscript.

Conflict of interests: the authors declare no potential conflict of interests.

Acknowledgements: the authors would like to thank Mrs. Caroline Edeh, for her support in reviewing the English text.

Conference presentation: part of this paper was presented at the XIX National Meeting of the Italian Society of Palliative Care (SICP), Turin, Italy, Oct. 2012.

Received for publication: 22 February 2013.

Revision received: 6 May 2013.

Accepted for publication: 7 May 2013.

This work is licensed under a Creative Commons Attribution NonCommercial 3.0 License (CC BY-NC 3.0).

CCopyright G. Arvia et al., 2013

Licensee PAGEPress, Italy

Italian Journal of Medicine 2013; 7:253-258

doi:10.4081/itjm.2013.253

\section{Introduction}

In recent years, there has been a growing interest and many resources have been invested in the care and management of cancer patients in the very advanced or terminal phase, with the objective of improving patient comfort and quality of life (QoL). Nevertheless, the therapeutic approach to clinically refractory cancer cachexia still represents an unmet need ${ }^{1}$ and, therefore, represents one of the most important research priorities in the field of palliative care. ${ }^{2}$ Unfortunately, clinical studies aimed at dealing with this are extremely scarce, both for nutritional and for pharmacological approach. With regards to nutritional support, there is no definitive evidence to support the use of parenteral nutrition (PN) in patients at end of life and, in general, long-term PN is recommended only in selected patients who are likely to die from starvation before tumor progression. ${ }^{3}$ Enteral and parenteral nutrition may help improve QoL, but these benefits appear to be limited. ${ }^{4}$ A Cochrane Systematic Review on the use of medically assisted nutrition in palliative care patients concludes that There are insufficient good quality studies to make any recommendations for practice. ${ }^{5}$ Therefore, according to a recent position paper, ${ }^{6}$ the decision to administer parenteral nutrition should be tailored to individual patients on a clinical basis and should be consistent with the goals of patient care.

As regards the pharmacological approach, there only three systematic reviews have been published. In the first, ${ }^{7}$ about thalidomide, there is inadequate evi- 
dence to recommend its use in clinical practice. In the second, ${ }^{8}$ the same conclusions are reported for the use of fish oil, while in the last review, ${ }^{9}$ about nonsteroidal anti-inflammatory drugs, some evidence is shown of positive therapeutic effects on QoL, performance status, inflammatory markers, and weight gain and survival, but there is insufficient evidence for widespread use in clinical practice.

\section{Methods of research}

A systematic search of the scientific literature was performed by consulting Pubmed ${ }^{\circledR}$ in the attempt to answer the questions concerning the effectiveness of pharmacological treatment of cancer cachexia in the very advanced phase, and the effectiveness of nutritional approach in the same context. Therefore, a complex search algorithm was used (Table 1) taking into account the following eligibility criteria: i) the clinical context (advanced or terminal phase or palliative care or hospice care); ii) the related pathology (cachexia or wasting syndrome); and iii) the therapeutic approach (pharmacological treatment or nutritional support).

The inclusion criteria of the search were: i) publications in English with an available abstract; ii) from between January 1972 to October 2012. The abstracts obtained were entered in a spreadsheet and analyzed, if necessary evaluating the full text. We used the following exclusion criteria for the abstract analysis: i) literature review papers; ii) studies not concerning the advanced phase; iii) phase II studies; iv) studies including patients with Karnofsky performance status $\geq 50 \%$; and v) studies allowing concomitant palliative chemotherapy.

After this selection procedure, the suitable papers were then analyzed in full text according to the PRISMA method, ${ }^{10}$ reporting the study design, the characteristics of included patients, the treatment arms, and the clinical results evaluated according to outcome: quality of life, symptom measurements, survival, adverse effects.

\section{Results}

The detailed Prisma flow chart is reported in Figure 1. A total of 255 records were identified through the first step of the Pubmed ${ }^{\circledR}$ search. Then, 6 additional records identified through other sources (reported in the bibliography of review articles) were added; 3 duplicate records were removed, leading to 258 screened records. In the second step, 244 records were excluded: 44 because they were not in English, 12 because they had no available abstract, 108 were literature reviews, 80 studies did not concern the advanced setup or were phase II studies or included pa- tients with Karnofsky performance status $\geq 50 \%$ or allowed concomitant palliative chemotherapy.

All the remaining 14 papers were read in full text. Ten of them were excluded from the final analysis because 4 were phase II studies ${ }^{11-14}$ (Table 2), 4 studies included patients with a Karnofsky performance status $\geq 50 \%,{ }^{15-18} 2$ studies included some patients concomitantly treated by palliative chemotherapy. ${ }^{19,20}$ The detailed characteristics of the remaining 4 studies included in the qualitative synthesis are reported in Table 3 while Table 4 shows the reported outcomes.

The first reported study ${ }^{21}$ concerned the use of megestrol acetate $160 \mathrm{mg}$ /day for ten days with crossover in patients with advanced non-hormone responsive solid tumors. An improvement in appetite $(\mathrm{P}=0.005)$, activity $(\mathrm{P}=0.007)$ and wellbeing $(\mathrm{P}=0.03)$ was registered, whereas no change in body weight, nutritional parameters, energy intake or QoL score was obtained. The second study ${ }^{22}$ concerned the comparison between supportive treatment plus melatonin 20 $\mathrm{mg}$ /day and supportive therapy alone. While there was no change in food intake, a greater than $10 \%$ weight loss was registered in $4 \%$ only of patients adding melatonin to supportive treatment, in comparison with $32 \%$ of patients submitted to supportive treatment alone $(\mathrm{P}<0.01)$. The third study ${ }^{23}$ was a placebo-controlled study on adenosine 5 '-triphosphate by intravenous intermittent slow infusion. A significant improvement in body weight $(\mathrm{P}=0.002)$, serum albumin level $(\mathrm{P}=0.006)$, muscular strength evaluated by a hand-held dynamometer $(\mathrm{P}=0.02)$ and in $\mathrm{QoL}$ score $(\mathrm{P}=0.0001)$ was registered during the trial period. A longer but not statistically significant survival (median

Table 1. The detailed Pubmed ${ }^{\circledR}$ search algorithm.

PUBMED search:

("palliative care"[All Fields] OR ("hospices"[MeSH Terms] OR "hospices"[All Fields] OR "hospice"[All Fields] OR "hospice care"[MeSH Terms] OR ("hospice"[All Fields]

AND “care"[All Fields]) OR "hospice care"[All Fields]) OR “terminal care"[All Fields] OR "terminally ill”[All Fields])

AND (“neoplasms”[MeSH Terms] OR “neoplasms"[All Fields] OR "cancer"[All Fields])

AND ((“cachexia”[MeSH Terms] OR "cachexia"[All Fields]) OR ("wasting syndrome"[MeSH Terms] OR ("wasting”[All Fields] AND "syndrome"[All Fields]) OR "wasting syndrome"[All Fields]))

AND (("therapy"[Subheading] OR "therapy"[All Fields] OR "treatment"[All Fields] OR "therapeutics"[MeSH Terms] OR "therapeutics"[All Fields]) OR ("therapy"[Subheading] OR "therapy"[All Fields] OR "therapeutics"[MeSH Terms] OR "therapeutics"[All Fields]) OR ("nutritional support"[MeSH Terms] OR ("nutritional"'[All Fields]

AND “support”[All Fields]) OR "nutritional support"[All Fields]) 
Table 2. List of the excluded full text studies.

\begin{tabular}{|c|c|c|}
\hline Author (ref.) & Treatment & Reasons for exclusion \\
\hline Strasser et al. ${ }^{11}$ & i.v. Ghrelin & Phase II \\
\hline Tassinari et al. ${ }^{12}$ & Thalidomide & Phase II \\
\hline Bruera et al. ${ }^{13}$ & Thalidomide & Phase II \\
\hline Hopkinson et al. ${ }^{14}$ & MAWE & Phase II \\
\hline Kraft et al. ${ }^{15}$ & L-Carnitine & $\mathrm{PS}>50 \%$ \\
\hline Daneryd et al. ${ }^{16}$ & Indomethacin $+/$ - erithropoietin & $\mathrm{PS}>50 \%$ \\
\hline De Conno et al. ${ }^{17}$ & Megestrol acetate & $\mathrm{PS}>50 \%$ \\
\hline Bruera et al. ${ }^{18}$ & Fish oil & $\mathrm{PS}>50 \%$ \\
\hline
\end{tabular}

Chasen et al 19

Peptide-nucleic acid OHR118

Some patients in palliative CT

Lundholm et al. ${ }^{20}$

Indomethacin + erithropoietin + nutritional support $+/$ - insulin

Some patients in palliative CT

i.v., intravenous; MAWE, Macmillan approach to weight loss and eating difficulties; PS, performance status score; CT, chemotherapy.

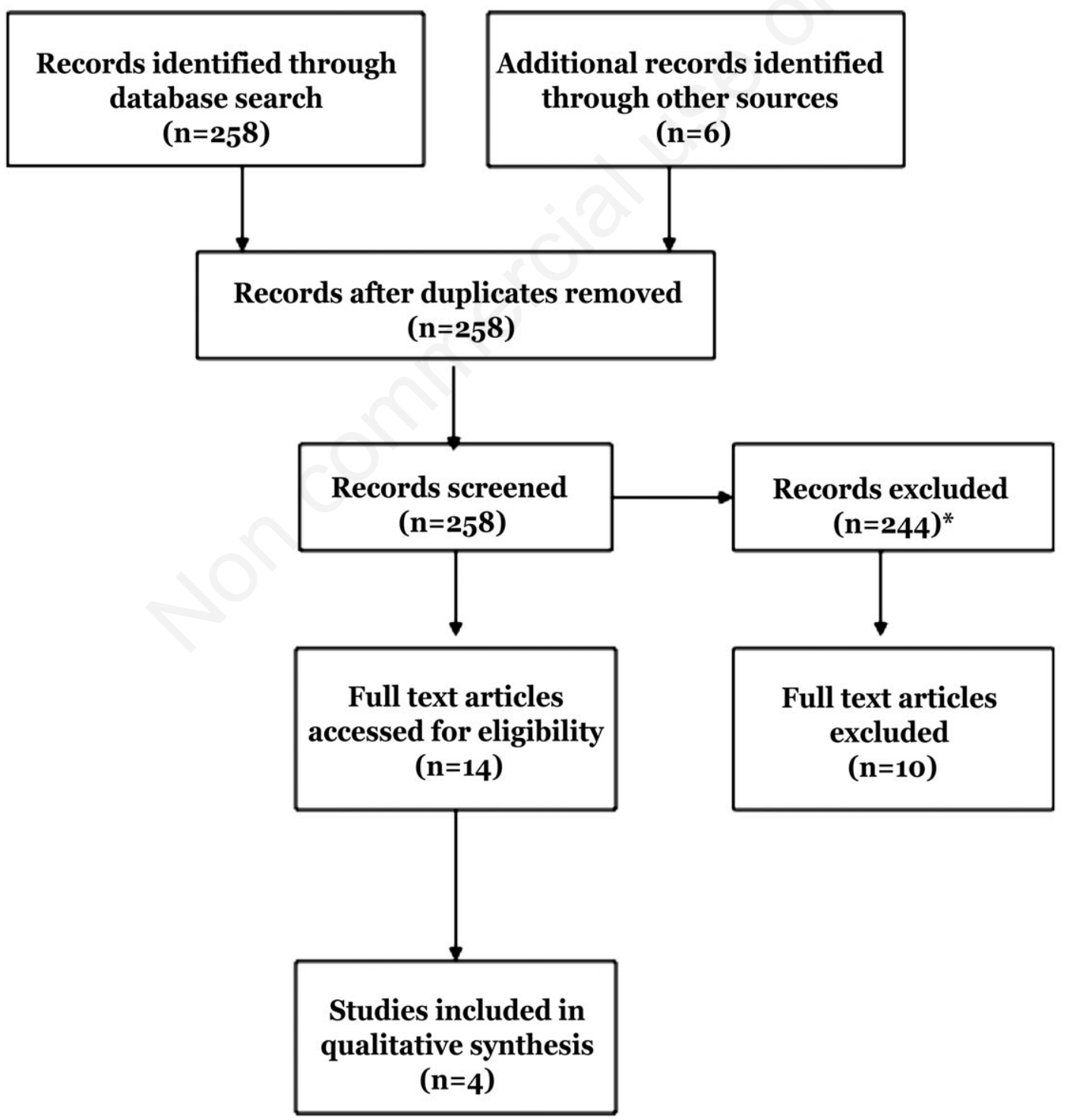

Figure 1. The Prisma flow-chart. *The details of the excluded studies are reported in the text. 
Table 3. Detailed characteristics of the studies included in qualitative synthesis.

\begin{tabular}{|c|c|c|c|c|c|c|c|}
\hline $\begin{array}{l}\text { Author, } \\
\text { year (ref.) }\end{array}$ & $\begin{array}{l}\text { Study } \\
\text { design }\end{array}$ & $\begin{array}{c}\text { Patients' } \\
\text { characteristics }\end{array}$ & $\begin{array}{l}\text { Total no. of } \\
\text { patients } \\
\text { included }\end{array}$ & $\begin{array}{l}\text { Evaluable } \\
\text { patients } \\
\text { (experimental } \\
\text { arm) }\end{array}$ & $\begin{array}{l}\text { Experimental } \\
\text { arm }\end{array}$ & $\begin{array}{c}\text { Evaluable } \\
\text { patients } \\
\text { (control arm) }\end{array}$ & $\begin{array}{l}\text { Control } \\
\text { arm }\end{array}$ \\
\hline $\begin{array}{l}\text { Bruera et al., } \\
1998^{21}\end{array}$ & $\begin{array}{l}\text { RCT phIII, } \\
\text { DB, cross }\end{array}$ & AST, NHST & 84 & 53 (cross) & $\begin{array}{c}\text { MEG } \\
160 \underset{\mathrm{mg} \times 3 / \mathrm{d} \times 10 \mathrm{dd}}{\text { then } \text { cross }}\end{array}$ & 53 & Placebo \\
\hline $\begin{array}{l}\text { Lissoni et al., } \\
1996^{22}\end{array}$ & RCT phIII & AST, OffTh & 100 & 45 & $\begin{array}{l}\mathrm{ST}+\text { melatonin } \\
20 \mathrm{mg} / \mathrm{d}\end{array}$ & 41 & ST alone \\
\hline $\begin{array}{l}\text { Agteresch et al., } \\
2000^{23}\end{array}$ & $\begin{array}{l}\text { RCT phIII, } \\
\text { open }\end{array}$ & $\begin{array}{l}\text { NSCLC stage } \\
\text { IIB-IV, OffTh }\end{array}$ & 58 & 28 & $\begin{array}{l}\text { ATP } 20 \rightarrow 75 \mu \mathrm{g} / \mathrm{kg} / \mathrm{min} \\
\quad \times 30 \text { h i.v. q } 2-4 \mathrm{wks} \\
\quad \times 10 \text { (tot. } 28 \mathrm{wks} \text { ) }\end{array}$ & in & Placebo \\
\hline $\begin{array}{l}\text { Lundholm et al., } \\
2004^{24}\end{array}$ & RCT phIII & $\begin{array}{c}\text { AST (mostly GI), } \\
\text { OffTh, WL }>5 \%\end{array}$ & 309 & 107 & $\begin{array}{c}\mathrm{INDO}+\mathrm{EPO} \\
(12-30 \mathrm{MU} / \mathrm{wk})+\mathrm{NS}\end{array}$ & 139 & INDO+EPO \\
\hline
\end{tabular}

RCT, randomized clinical trial; phIII, phase III; DB, double blind; cross, cross-over; AST, advanced solid tumors; NHST, not hormone-sensitive tumors; MEG, megestrol acetate; d, daily; dd, days; OffTh, off therapy; NSCLC, non-small cell lung cancer; ATP, adenosine 5'-triphosphate; wks, weeks; GI, gastrointestinal; WL, weight loss; INDO, indomethacin; EPO, recombinant human erythropoietin; wk, weekly; NS, nutritional support (orally, or home parenteral nutrition).

Table 4. The reported outcomes of the studies included in qualitative synthesis.

\begin{tabular}{lcccc}
\hline Author, year (ref.) & QoL & Symptoms & Survival & Adverse effects \\
\hline Bruera et al., 1998 & $\begin{array}{c}\text { Better activity } \\
\text { and wellbeing. } \\
\text { No change in FLIC } \\
\text { scores }\end{array}$ & $\begin{array}{c}\text { Improvement in } \\
\text { appetite No change } \\
\text { in BW, nutritional } \\
\text { parameters, energy intake }\end{array}$ & NR & NR \\
\hline Lissoni et al., 1996 & NR & $\begin{array}{c}\text { Reduction in WL; } \\
\text { no change in food intake }\end{array}$ & NR & No melatonin toxicity \\
\hline Agteresch et al., 200023 & $\begin{array}{c}\text { Mantained physical } \\
\text { QoL score during } \\
\text { treatment period }\end{array}$ & $\begin{array}{c}\text { Gain in BW, albumin, } \\
\text { muscular strength }\end{array}$ & $\begin{array}{c}\text { Longer for } \\
\text { experimental arm pts }\end{array}$ & $\begin{array}{c}\text { Chest discomfort, dyspnea, } \\
\text { flushing, nausea, headache, } \\
\text { sweating, mood alteration, } \\
\text { palpitations, injection side reaction }\end{array}$ \\
\hline Lundholm et al., 200424 & NR & $\begin{array}{c}\text { Improved energy } \\
\text { balance; no change in BW }\end{array}$ & $\begin{array}{c}\text { Longer for experimental } \\
\text { arm patients }\end{array}$ & NR \\
\hline
\end{tabular}

QoL, quality of life score; FLIC, Functional Living Index-Cancer; BW, body weight; NR, not reported; WL, weight loss.

5.6 vs 4.7 months; $\mathrm{P}=0.51$ ) was reported in the experimental arm. The last study ${ }^{24}$ evaluated a combination of a COX inhibitor (indomethacin, $50 \mathrm{mg}$ twice daily) and recombinant erythropoietin (15-40,000 IU/week administered subcutaneously) along with oral nutritional support and home total parenteral nutrition. The addition of nutrition led to a prolonged survival $(\mathrm{P}<0.01)$ that was accompanied by improved energy balance $(\mathrm{P}<0.001)$ and a greater maximum exercise capacity $(\mathrm{P}<0.04)$.

\section{Discussion}

This systematic review has some methodological weaknesses that make the interpretation of results difficult. First, the apparently negative results of our systematic review might be a consequence of the choice of too wide a context of research, including studies with heterogeneous inclusion criteria and end points. Splitting the literature analysis into two parts, i.e. efficacy of drugs and efficacy of the nutritional treatment, might have led to different results. Furthermore, the search was limited to Pubmed, therefore, we cannot exclude the possibility that we might have lost some relevant articles cited on other databases. Finally, data collection and analysis were performed by only one author (GL) and this could have led to a possible misinterpretation of the results.

Nevertheless, the above reported data show that even now there is a complete lack of studies directed at verifying the efficacy of pharmacological or nutritional treatment for cancer cachexia in the very advanced or terminal phase. In particular, as regards drugs, the scarcity of available data does not allow us to draw any conclusions that could be translated into 
clinical practice. The single study about progestins ${ }^{21}$ confirms their efficacy, according to a wide metaanalysis, ${ }^{25}$ even if the latter was not aimed specifically at the very advanced phase.

Concerning the nutritional approach, the single reported study ${ }^{24}$ seems to show an advantage in its use, even if the Cochrane review ${ }^{5}$ and the available guidelines $^{3,26}$ seem to exclude a real advantage for parenteral nutrition in the refractory phase of cancer cachexia.

In the clinical context, a careful nutritional evaluation of all cancer patients remains a general objective for improvement, and it should lead to an early clinical staging of cachexia before the initiation of the precachexia-cachexia-refractory cachexia chain. ${ }^{27}$

The optimal management of the patient in the particular context of palliative care requires adequate education and counseling for patients and families, and a significant interaction between patients, caregivers and the medical staff.

The interruption of artificial support could be a cause of distress for patients and family members. Moreover, the uncertainty about the evaluation of prognosis, psychosocial factors and the perceived benefits of artificial nutrition support its employment in terminally ill patients. In the light of this, we can reasonably recommend a 3-step approach for clinical practice: a careful pre-treatment evaluation of patients with any grade of cancer cachexia (including nutritional status, and evaluation of performance status and of the prognostic factors), a prognosis-oriented decision-making process (excluding from artificial support those patients in the end-of-life phase), and, finally, an informed consent for patients and families on the consequences of cancer cachexia and its treatment, as regards quality and duration of life.

In consideration of this approach, in case of uncertainty about the benefits and risks of parenteral nutrition in the individual patient, it would be appropriate to have a brief trial period after which the clinical benefits and risks could be reassessed. The final decision should also take into account the emotional involvement of the patient and the family, in complete agreement with the conclusions of the position paper already referred to. ${ }^{6}$ Once again, even though we recognize the complexity involved in carrying out such studies, we are waiting hopefully for specific studies in the context of cancer cachexia in the very advanced or terminal phase.

\section{References}

1. Fearon K, Strasser F, Anker SD, et al. Definition and classification of cancer cachexia: an international consensus. Lancet Oncol 2011;12:489-95.

2. Sigurdardottir KR, Haugen DF, Bausewein C, et al. A pan-European survey of research in end-of-life cancer care. Support Care Cancer 2012;20:39-48.
3. Bozzetti F, Arends J, Lundholm K, et al. ESPEN Guidelines on Parenteral Nutrition: non-surgical oncology. Clin Nutr 2009;28:445-54.

4. Morss Dy S. Enteral and Parenteral nutrition in terminally ill cancer patients: a review of the literature. Am J Hosp Palliat Care 2006;23:369-77.

5. Good P, Cavenagh J, Mather M, Ravenscroft P. Medically assisted nutrition for palliative care in adult patients. Cochrane Database Syst Rev 2008;4:CD006274.

6. Dev R, Dalal S, Bruera E. Is there a role for parenteral nutrition or hydration at the end of life? Curr Opin Support Palliat Care 2012;6:365-70.

7. Reid J, Mills M, Cantwell M, et al. Thalidomide for managing cancer cachexia. Cochrane Database Syst Rev 2012;4:CD008664.

8. Ries A, Trottenberg P, Elsner F, et al. A systematic review on the role of fish oil for the treatment of cachexia in advanced cancer: an EPCRC cachexia guidelines project. Palliat Med 2012;26:294-304.

9. Reid J, Hughes CM, Murray LJ, et al. Non-steroidal anti-inflammatory drugs for the treatment of cancer cachexia: A systematic review. Palliat Med 2012. [Epub ahead of print].

10. Moher D, Liberati A, Tetzlaff J, Altman DG. The PRISMA Group; Preferred Reporting Items for Systematic Reviews and Meta-Analyses: The PRISMA Statement. PLoS Med 2009;6:e1000097.

11. Strasser F, Lutz TA, Maeder MT, et al. Safety, tolerability and pharmacokinetics of intravenous ghrelin for cancer-related anorexia/cachexia: a randomised, placebocontrolled, double-blind, double-crossover study. Br J Cancer 2008;9:300-8.

12. Tassinari D, Santelmo C, Tombesi P, Sartori S. Thalidomide in the treatment of cancer cachexia. J Palliat Care 2008;24:187-9.

13. Bruera E, Neumann CM, Pituskin E, et al. Thalidomide in patients with cachexia due to terminal cancer: preliminary report. Ann Oncol 1999; 10:857-9.

14. Hopkinson JB, Fenlon DR, Okamoto I, et al. The deliverability, acceptability, and perceived effect of the Macmillan approach to weight loss and eating difficulties: a phase II, cluster-randomized, exploratory trial of a psychosocial intervention for weight- and eating-related distress in people with advanced cancer. J Pain Symptom Manage 2010;40:684-95.

15. Kraft M, Kraft K, Gärtner S, et al. L-Carnitine-supplementation in advanced pancreatic cancer (CARPAN) a randomized multicentre trial. Nutrition J 2012;11:52.

16. Daneryd P, Svanberg E, Körner U, et al. Protection of metabolic and exercise capacity in unselected weightlosing cancer. Cancer Res 1998;58:5374-9.

17. De Conno F, Martini C, Zecca E, et al. Megestrol acetate for anorexia in patients with far-advanced cancer: a double-blind controlled clinical trial. Eur J Cancer 1998; 34:1705-9.

18. Bruera E, Strasser F, Palmer JL, et al. Effect of fish oil on appetite and other symptoms in patients with advanced cancer and anorexia/cachexia: a double-blind, placebo-controlled study. J Clin Oncol 2003;21:129-34.

19. Chasen M, Hirschman SZ, Bhargava R. Phase II study of the novel peptide-nucleic acid OHR118 in the management of cancer-related anorexia/cachexia. J Am Med Dir Assoc 2011;12:62-7. 
20. Lundholm K, Körner U, Gunnebo L, et al. Insulin treatment in cancer cachexia: effects on survival, metabolism, and physical functioning. Clin Cancer Res 2007; 13:2699-706.

21. Bruera E, Ernst S, Hagen N, et al. Effectiveness of megestrol acetate in patients with advanced cancer: a randomized, double-blind, crossover study. Cancer Prev Control 1998;2:74-8.

22. Lissoni P, Paolorossi F, Tancini G, et al. Is there a role for melatonin in the treatment of neoplastic cachexia? Eur J Cancer 1996;32A:1340-3.

23. Agteresch HJ, Dagnelie PC, van der Gaast A, et al. Randomized clinical trial of adenosine 5 '-triphosphate in patients with advanced non-small-cell lung cancer. J Natl Cancer Inst 2000;92:321-8.

24. Lundholm K, Daneryd P, Bosaeus I, et al. Palliative nu- tritional intervention in addition to cyclooxygenase and erythropoietin treatment for patients with malignant disease: Effects on survival, metabolism, and function. Cancer 2004;100:1967-77.

25. Maltoni M, Nanni O, Scarpi E, et al. High-dose progestins for the treatment of cancer anorexia-cachexia syndrome: a systematic review of randomised clinical trials. Ann Oncol 2001;12:289-300.

26. NCCN Clinical Practice Guidelines in Oncology: Palliative Care, version 2, 2012. Available from: http://www. nccn.org/professionals/physician_gls/pdf/palliative.pdf

27. Vigano A, Del Fabbro E, Bruera E, Borod M. The cachexia clinic: from staging to managing nutritional and functional problems in advanced cancer patients. Crit Rev Oncog 2012;17:293-303. 